Vol. XXI / № 1 / 2007 / 59-81

\title{
Prisión política y tortura: desde las intervenciones psicosociales a las políticas de reparación
}

\author{
Marcela Cornejo, ${ }^{*}$ Rodrigo Rojas, ,* María Ester Buzzoni, ,** \\ Francisca Mendoza, Mariella Concha y Catalina Cabach****
}

\begin{abstract}
RESUMEN
A la fecha, desde el Estado se han implementado tres instancias relativas a la verdad y la reparación de las violaciones a los derechos humanos cometidas durante la dictadura militar, siendo la más reciente la Comisión Nacional sobre Prisión Política y Tortura (CNPPT). En este trabajo se analiza específicamente el fenómeno de la prisión política y la tortura, considerándolo un fenómeno sociopolítico, que determinó experiencias traumáticas con graves consecuencias psicosociales, tanto en las víctimas directas, como en los grupos primarios de apoyo y en la sociedad en su conjunto. Se discuten los ejes centrales y los límites de algunas experiencias de intervención terapéutica implementadas con estas personas. Finalmente, se examina lo que fue la experiencia de la CNPPT, cuyo Informe se hizo público en noviembre de 2004, analizando las particularidades de su funcionamiento y cuál ha sido su impacto en las propias víctimas, en la sociedad y en las políticas de reparación y verdad.
\end{abstract}

Palabras clave:

- Prisión política y tortura • verdad y reparación • trauma psicosocial • Comisión Nacional sobre Prisión Política y Tortura

* Psicóloga Escuela de Psicología Pontificia Universidad Católica de Chile, doctora en Ciencias Psicológicas Universidad Católica de Lovaina; académica Escuela de Psicología Pontificia Universidad Católica de Chile. Este trabajo fue realizado en el marco del Proyecto de Investigación "Del testimonio al relato de vida: procesos elaborativos en profesionales de la Comisión Nacional sobre Prisión Política y Tortura”, cuyo piloto implementado el año 2006 fue financiado por la Dirección de Investigación y Postgrado de la Pontificia Universidad Católica de Chile. La correspondencia relativa a este artículo debe ser enviada a Marcela Cornejo, investigadora responsable del proyecto. E-mail: marcela@uc.cl

** Psicólogo, diplomado en Relatos de Vida Escuela de Psicología Pontificia Universidad Católica de Chile.

*** Psicóloga Universidad Diego Portales, magíster (c) en Psicología Clínica Escuela de Psicología Pontificia Universidad Católica de Chile.

**** Estudiantes de pregrado Escuela de Psicología Pontificia Universidad Católica de Chile. 
$D_{\text {urante el período de las dictaduras latinoamericanas, las prácticas represivas que se }}$ implementaron en contra de disidentes políticos y amplios sectores de la población, tortura, exilio, prisión política, muerte y desaparición de personas, se extendieron masivamente.

En Chile, en el año 2003, al momento de conmemorarse 30 años del golpe de estado de 1973, se formó la Comisión Nacional sobre Prisión Política y Tortura (en adelante CNPPT), cuya misión fue hacer un catastro y proponer medidas de reparación para las personas que habían sido víctimas de prisión política y tortura (en adelante PPT). Por primera vez se producía en el país un reconocimiento público y oficial a estas prácticas en específico, así como la asunción de la responsabilidad del estado en ellas.

Este trabajo busca exponer y analizar el particular escenario socio-histórico en el que se instala la experiencia de la CNPPT, aludiendo a sus especificidades, como el trabajar sobre la PPT, con sobrevivientes de dichas prácticas, resituándolas desde una etiología social, analizando sus implicaciones singulares y colectivas. Para esto, se realizará un recorrido a través de las características de la PPT, sus consecuencias individuales y sociales, el trabajo de organizaciones de derechos humanos y salud mental sobre estas prácticas y, por último - a partir del trabajo realizado por la CNPPT y su impacto-, se aborda la línea de las políticas de verdad y reparación del estado para enfrentar las violaciones a los derechos humanos.

\section{Prisión política y tortura: consecuencias de un fenómeno sociopolítico}

En Chile, PPT fueron prácticas masivas, sistemáticas y organizadas como políticas de Estado durante la época de la dictadura (1973-1990). En este contexto, decenas de miles de personas resultaron directamente violentadas, daño que también se extendió a familiares, amigos y cercanos, así también como al cuerpo social en su conjunto (CNPPT 2004).

Esta última situación resalta la naturaleza social y política de este fenómeno: la PPT tuvo como objetivo no sólo ejercer un daño sobre las víctimas, sino que el propio sufrimiento de estas personas fue instrumentalizado para afectar también a otros (CNPPT 2004). Estas prácticas se inscribieron entonces como estrategias de control social, cuya finalidad era sostener un régimen político, insostenible por mecanismos legítimos.

Se trató de políticas de terror que, como señala Gómez (1985) se caracterizaron por al menos cuatro elementos: constituir fenómenos políticos, que implicaron para las víctimas experiencias límites de indefensión, en las cuales la relación entre torturador y torturado produjo una extrema perturbación de los vínculos y cuyo ejercicio era factible que provocara múltiples consecuencias en las víctimas. 
En el caso de las personas que sufrieron directamente la PPT, no sólo registraron daños debido a la agresión física, sexual o psicológica a las que fueron sometidas, sino que sus secuelas tuvieron un carácter global, afectando a las personas en su integridad física, emocional, existencial y social (Rojas 1994). Así también, las resultantes producto de la PPT no se restringieron sólo al momento del sometimiento a estas prácticas, sino que se extendieron en el tiempo, manteniendo y agravando el sufrimiento provocado.

Ahora bien, es necesario precisar que la distinción entre las consecuencias de la PPT que podrían estimarse inmediatas (por ejemplo, lesiones corporales o pérdida de empleo) y las secundarias (miedo crónico) o indirectas (ruptura de vínculos sociales) no constituye una diferenciación tajante, en tanto todas ellas resultan funcionales al propósito, ya mencionado, que se buscaba cumplir a través de estas prácticas.

Pero no sólo fue la experiencia de haber sufrido PPT la que provocó daño a sus víctimas, también se produjo durante mucho tiempo un proceso de victimización desde el silencio, la negación y la impunidad que se ha impuesto socialmente sobre estos hechos en el país.

A continuación se revisarán diversas secuelas que la PPT provocaron tanto en las víctimas como en la sociedad chilena en su conjunto, tomando como punto de partida el análisis de la naturaleza traumática de estas prácticas.

\section{PPT: experiencias traumáticas de origen social}

Tanto la tortura como la prisión política (que en muchos casos constituyó una continuación de la tortura) buscaron generar en la persona afectada una desorganización total. Las víctimas se encontraron en una situación nunca antes vivida, un mundo caótico repleto de acciones inesperadas, arbitrarias e imprevisibles, cargadas de violencia y de agresión por parte de otro ser humano.

En este contexto, todos los elementos de la experiencia (cuerpo, vínculos significativos, incluso servicios básicos como alimentación y atención médica) fueron utilizados como mecanismos de amenaza, manipulación y tortura, frente a lo cual la persona se encontraba totalmente inerme. La angustia, el dolor y el pánico daban cuenta de una situación siniestra, carente de representación mental homologable. Su dimensión desestructurante abarcaba no sólo el ámbito psíquico, sino también el nivel emocional, la identidad, la experiencia corporal, las relaciones humanas y los sistemas de valores (Espínola, Gil, Klingier, Leone 1985; Rojas 1994).

PPT pueden comprenderse, entonces, como experiencias de carácter traumático, capaces de provocar un colapso transitorio en la estructura psíquica, el que puede perdurar incluso tras la reorganización del psiquismo, alterando el funcionamiento previo de la persona y manteniendo sus efectos a largo plazo (Lira 1992a). 
Pero la especificidad de estas experiencias traumáticas es que fueron situaciones que se generaron en un contexto social amenazante, como lo fue la dictadura chilena. Por esta razón, diversos autores han conceptualizado este fenómeno como una experiencia de "traumatización extrema” (Lira 1992b, Riquelme y Cruz 2003), lo cual subraya la ruptura radical en los proyectos vitales y el impacto destructivo continuado en la identidad de las personas y sus relaciones familiares y sociales, connotando el origen sociopolítico del trauma, así como que la sociedad en su conjunto resulta impactada, si bien los efectos físicos y psicológicos se manifiestan principalmente en las víctimas directas.

De esta manera, es el contexto sociopolítico el que adquiere una dimensión primaria y determinante en la etiología de estas experiencias: el punto de arranque del trauma está en la sociedad misma, es un 'trauma psicosocial', como reconoce Martín-Baró (en Madariaga 2002), se trata de un proceso que afecta a toda la sociedad, pero de manera diferenciada a distintos actores sociales.

Consecuentemente, puede precisarse que reconociendo la etiología social de la PPT, al describir sus secuelas se considera que los síntomas o síndromes que presenta una persona luego de haber sido torturada no poseen un carácter de anormalidad o enfermedad (Rojas 1994), sino que son producto de un contexto en extremo anormal (Lira, Weinstein, Salamovich 1986).

\section{Consecuencias de la PPT}

Las consecuencias de la PPT pueden describirse en diferentes niveles: individual, en los grupos primarios de apoyo y en la sociedad.

Entre las consecuencias individuales que diversos autores han reportado en víctimas de PPT (Becker, Weinstein 1986; CNPPT 2004; Collarte, Villanueva 1992; Ibacache, Meléndez, Castaldi, Cabrera, Vega 1991; Gómez 1985; Kordon, Edelman 2005b [1995]; Lira et al. 1986; Rey 1985) se encuentran tanto sintomatología aguda ligada al impacto inmediato de la experiencia traumática (lesiones físicas, angustia severa, vivencias paranoides, alteraciones psicosomáticas), como también consecuencias a mediano y largo plazo en los diferentes ámbitos: físico (lesiones, enfermedades y discapacidades en diversos sistemas del organismo), sexual (las que muchas veces afectaron las relaciones de pareja), cognitivo (alteraciones en la función de alerta, concentración, memoria, orientación espacio-temporal, sintomatología de repetición como pesadillas o flashbacks), emocional (labilidad afectiva, ánimo depresivo, angustia y reacciones fóbicas) y existencial (alteraciones en la identidad, quiebres en la continuidad y realización de proyectos vitales, y un profundo cuestionamiento de los valores y los principios que sustentan la convivencia humana).

Respuestas adaptativas que en su momento constituyeron medios de supervivencia frente a estas experiencias (por ejemplo, el miedo o la disociación), al sostenerse en el 
Vol. XXI / № 1 / 2007 / 59-81

tiempo sobrepasan su carácter reactivo estableciéndose como estados estables de funcionamiento, con altos costos para la salud mental de las personas (Agger, Jensen 1996).

De esta forma, el miedo se instaló como un estado emocional crónico, acentuando las vivencias de desamparo, terror e inseguridad, lo que generó sentimientos de desconfianza hacia los otros, dificultando las relaciones interpersonales, además de la pérdida de redes de apoyo y grupos de referencia.

En los entornos cercanos de las víctimas, las consecuencias de la PPT se expresaron a través de dinámicas tales como irrupción de expresiones de rabia, impotencia y miedo sobre las familias, reproducción en el grupo familiar de las experiencias represivas, lo que acrecentaba los sentimientos de impotencia y culpabilidad. Puesto que el propio sufrimiento producto de la PPT pudo ser considerado dañino para otros, el silencio autoimpuesto sobre esta experiencia pudo distanciar y rigidizar las relaciones familiares, destruyendo los vínculos primarios de apoyo. Sobre las familias comúnmente recayó, además, marginalización, estigmatización y descenso social, lo cual representó constantes dificultades para reorganizar la vida y cronificó aún más los daños (Agger, Jensen 1996; CNPPT 2004; Gómez 1985; Ibacache et al. 1991).

En la sociedad, la práctica de la PPT produjo una convivencia social marcada por la amenaza vital, la desconfianza, la inseguridad y la soledad, experiencias que irrumpieron en la cotidianidad de los ciudadanos como fenómenos masivos, colectivos y perceptibles, a la vez que privados, encubiertos y renegados. Se generó una desarticulación de las redes de apoyo, de las estructuras de participación social y del sentimiento colectivo de pertenencia (CNPPT 2004, Ibacache et al. 1991, Lira et al. 1986), todo lo cual contribuyó a la desintegración y fragmentación social.

\section{Negación social: privatización del daño y repliegue de los sujetos políticos}

Las consecuencias de la PPT no se agotan en la descripción anterior, puesto que si bien algunas de ellas corresponden a su impacto traumático, las condiciones sociales en que debió elaborarse esta experiencia generaron nuevas secuelas. Como señala Ferenczi: "La especificidad del concepto de trauma radica en que lo patógeno no es la sola experiencia traumática sino la resistencia del ambiente humano a mantener un espacio de amparo al sujeto traumatizado, que en definitiva se instala como abandono y desmentida de las experiencias del sujeto" (en Rojas 2000:183; las cursivas son nuestras).

En este sentido, las consecuencias que surgen a partir de la experiencia de la PPT fueron agravadas por la negación sistemática de estos hechos en el país, lo que le reafirmó su carácter traumático (Kordon, Edelman 2005b [1995]). Este silenciamiento social, tanto de las prácticas de violencia política por parte del estado, como del sufrimiento de las víctimas, profundizó las sensaciones de impotencia, desamparo y marginación en quienes las sufrieron (Kordon, Edelman 2005c [1995]). 
En este sentido, es posible pensar en una dinámica social desmentida ${ }^{1}$ de estos hechos, la que fue dejando a las víctimas con un vacío, una falta de representación y de significación de la experiencia, lo cual impidió su tramitación y reparación (Kordon, Edelman 2005c [1995]). Pues además de su carácter impensable (dimensión irrepresentable a causa de su origen siniestro y las emociones intolerables a las que permanece ligada), esta experiencia asume también un carácter impensado, es decir, permanece alojada en el aparato psíquico y sólo puede adquirir significación y ser transformada en pensamiento cuando el contexto lo permite (Puget 2006). El contexto instaló una profunda represión normativa que no permitió hablar ni pensar sobre aquello. De esta forma, este saber permanece en el plano de lo no decible, lo cual impide confirmar la realidad y delimitar lo real y lo fantaseado de aquello que se vivió.

El trauma, los temores, las desconfianzas, no se sabe si son realmente justificados o no (Kordon, Edelman 2005a [1986]; Lira, Weinstein, Salamovich 1986), la credibilidad en los hechos y el sufrimiento de las víctimas son cuestionados, todo lo cual implica una continuidad de la tortura en las víctimas. Así — como señala Vidal (1989, en Lira 1992a) —, se produce un efecto cataclísmico sobre la realidad social, al dislocar todos los elementos de referencia subjetiva.

Además, el silencio y la impunidad generan en las víctimas el sentimiento de ser portadores de una historia traumática que no puede ser compartida con los demás, lo cual también se traduce en vivencias de exclusión, aislamiento o resentimiento frente al entorno, y en el encierro en grupos de pertenencia que comparten la misma problemática (Kordon, Edelman 2005b [1995]).

Por otra parte, la desmentida de estos hechos provoca una inducción a la culpabilidad de las víctimas respecto de su propio sufrimiento y una psiquiatrización de las mismas, dinámica que diversos autores (CNPPT 2004; Ibacache et al. 1991; Kordon, Edelman 2005a [1986]; Riquelme, Cruz 2003) han descrito como una privatización del daño, fenómeno en el cual las personas viven las consecuencias de la PPT como incapacidades propias y no como resultado de ser víctimas de una situación siniestra, producto de la falta de reconocimiento social de la situación traumática. Así, los actos punibles del estado se transforman en duelos personales, en pérdidas privadas, hecho que intensifica los daños en las víctimas y genera —entre otras consecuencias - culpa, dinámicas autodestructivas individuales y familiares, inducción a guardar silencio, estigmatización sobre los afectados y, a nivel social, olvido, disolución de responsabilidades ${ }^{2}$ y la consideración de la disidencia política como enfermedad mental o corrupción moral.

1 En el sentido psicoanalítico de un mecanismo característicamente perverso que reniega de un hecho existente pero que, en su misma negación, lo afirma (Freud 1927).

2 Esto también constituye un mecanismo propio de lo perverso, en tanto se pretende renegar de toda diferencia (Chasseget-Smirgel 1986); en este caso, anulando las distinciones entre víctimas, victimarios y cómplices bajo el aforismo 'todos somos culpables'. 
De esta manera, el conflicto político — innombrable - se instala como un conflicto psíquico, individual. Se agrava así el trauma, dejándolo sin soporte representacional al eliminar la dimensión política que lo sustenta, proceso que además de perpetuar el daño a las víctimas directas, niega la condición de víctima de la sociedad en su conjunto, al no permitir historizar la violencia social sufrida (Azócar, Casté, Soza 2003) y nos deja, a decir de Milos (2003), huérfanos de memoria.

Todas estas consecuencias no son secundarias, sino que constituyen también objetivos de la violencia institucionalizada y legitimada por el estado. Precisamente, la PPT no sólo buscan arruinar a la persona en el ámbito físico, psicológico y a nivel del apoyo social, sino que intentan anular el rol social y político activo de las personas (Collarte, Villanueva 1992; Lira et al. 1986) a través de una trilogía de destinos, encierro, destierro o entierro. ${ }^{3}$ Dado que se había actuado grupalmente en relación a un ideal y un quehacer colectivos, lo que se intentó entonces fue destruir sistemáticamente aquel vínculo social y político entre los ciudadanos (Espínola et al. 1991).

Para esto, se violentó no sólo a los líderes o participantes más activos, sino que en una gran cantidad de casos las víctimas de PPT fueron personas que no militaban en partidos políticos ni adscribían activamente al proyecto de la Unidad Popular, vale decir, personas que podrían definirse como ciudadanos comunes, ${ }^{4}$ para quienes lo sufrido tuvo un carácter aún más incomprensible y traumático. El Informe de la CNPPT da cuenta de un gran número de víctimas que sólo al momento de entregar su testimonio comprendió de lo que se les estaba acusando al momento de su detención.

De esta forma, en tanto se intenta destruir principalmente la condición de sujeto político de cada una de las víctimas y, a través del terror, la de muchos otros, PPT fueron prácticas destinadas a debilitar también el cuerpo social en su conjunto, considerando que la sociedad es el espacio habitado y constituido, precisamente, por aquellos sujetos políticos.

\section{Experiencias de intervención con personas víctimas de PPT}

La situación de represión política vivida por centenares de personas comenzó a hacerse visible a pocos meses de la instalación del gobierno dictatorial. Este contexto de represión

3 Precisamente, las penas aflictivas, el exilio y la muerte son los mecanismos legales que hacen perder la ciudadanía, además de intentar amedrentar a las personas para impedir su participación social activa.

4 Emblemáticos resultan en este sentido allanamientos masivos a campamentos, tomas o poblaciones, y detenciones realizadas en localidades rurales, donde la incomprensión de la situación resultaba incluso mayor. Ambos ejemplos dan cuenta de la falsedad del argumento de la 'selectividad' de estas prácticas (que solía ser la justificación de las detenciones) y afirman el intento de implantar el terror a través de estas políticas. En este sentido, la película Machuca, del director chileno Andrés Wood (2004) entrega una clara representación de lo aquí expuesto. 
dejó a una parte considerable de la población sumida en el desamparo, instalando una atmósfera de amenaza y miedo, principalmente debido a las noticias recurrentes de desapariciones y encarcelamientos de personas, sin el resguardo de sistemas regulares de justicia (Lira, Becker, Castillo 1991). En este ambiente, grupos de profesionales de salud mental buscaron responder a la necesidad de generar espacios de protección de la salud y la integridad de quienes estaban expuestos al peligro de perder la vida o la libertad. ${ }^{5}$ Surgió así la necesidad de sistematizar el trabajo realizado y generar un cuerpo de conocimientos que permitiera comprender las dinámicas psicosociales y políticas implicadas en la tortura (Garcés, Nicholls 2005). Las opciones teóricas y prácticas develaron una dimensión ética del abordaje, la que guiaba la acción e indicaba las implicaciones y consecuencias de asumir una opción teórica o un modo de intervención en lugar de otro.

\section{Construcción de un marco conceptual: la tortura como trauma psicosocial}

A partir de la toma de posición frente a la realidad sociopolítica, la tortura fue comprendida como una acción deliberada, dirigida a la destrucción del individuo, con implicaciones que incidían sobre la identidad de los sujetos, sobre sus valores y sobre sus vínculos colectivos (Lira et al. 1991).

Estos profesionales discutieron las categorías diagnósticas de los síndromes psiquiátricos (por ejemplo, el trastorno por estrés postraumático), ya que les resultaban insuficientes para dar cuenta de la problemática de estos pacientes y sus necesidades. Consecuentes con esta perspectiva ética, definieron la tortura como una experiencia de traumatización extrema (Lira et al. 1991), tomando el concepto desde la psicología de la guerra de Bettelheim, donde lo insostenible de la experiencia apunta a la vulnerabilidad en que se encuentra la persona, debiendo optar entre ser fiel a sus valores y renunciar a ellos para evitarse el dolor y la muerte.

En la búsqueda de un marco conceptual más adecuado para abordar los problemas psicológicos que se derivan de contextos socio-históricos, como lo fue la PPT en Chile, estos profesionales complementaron este concepto clínico, cuyo énfasis estaba puesto en la subjetividad de las víctimas, con el de trauma psicosocial, propuesto por Martín Baró (Madariaga 2002; Lira et al. 1991; Kordon, Edelman 2005a [1986]), cuyo énfasis está

\footnotetext{
Lo aquí presentado surge de la reflexión de organizaciones que sistematizaron su experiencia de abordaje del fenómeno de la PPT: la Fundación de Ayuda Social de Iglesias Cristianas, FASIC, (www.fasic.org); el Centro de Salud Mental y Derechos Humanos, CINTRAS (www.cintras.tie.cl); el Instituto Latinoamericano de Salud Mental y Derechos Humanos, ILAS (www.ilas.cl), y por último, el Equipo Argentino de Trabajo e Investigación Psicosocial, EATIP (www.eatip.org.ar). Se han escogido estas organizaciones debido a su significativo aporte a la construcción de un saber acerca de la intervención terapéutica y las particulares condiciones en que esta se realiza en la elaboración de experiencias relacionadas con PPT.
} 
Vol. XXI / № 1 / 2007 / 59-81

puesto tanto en los factores sociales y políticos implicados en la experiencia subjetiva individual, como en el impacto del trauma en las relaciones y prácticas a nivel social.

Martín-Baró (en Cornejo, Morales, Sharim, Kovalskys 2006) propone tres aspectos definitorios del concepto de trauma psicosocial: su carácter dialéctico, que implica integrar la dimensión histórica y dinámica; la necesidad de identificar las causas sociales que lo sustentan; y, finalmente, que la presencia de eventos traumáticos afecta el carácter que asumen las relaciones sociales y su mantenimiento a través del tiempo.

Desde esta perspectiva, se podría entender la situación de tortura como una relación traumatizante entre el estado o agentes del estado y personas que fueron sometidas a esta práctica producto de su filiación política o su pertenencia a determinados sectores sociales. El origen y la mantención del trauma se sitúa, entonces, en las relaciones y prácticas sociales de determinado contexto socio-histórico. Si bien los efectos físicos y psicológicos se manifiestan principalmente en el sujeto sometido, es la sociedad en su conjunto la que resulta impactada. El trauma está inserto en la trama social.

En consecuencia, desde esta opción teórica, los profesionales sostuvieron que ignorar el escenario histórico llevaría a simplificar la situación traumática, situándola como un hecho aislado y sin conexión con los procesos sociales que la sostenían. Esta postura rigió la comprensión etiológica y el abordaje de los síntomas, reconociendo la dimensión sociopolítica de la tortura y al individuo en su dimensión social. El malestar provocado ya no se comprendería como un grupo de síntomas aislados, sino que su abordaje implicaría dirigirse al trauma psicosocial producido.

\section{La construcción de un vínculo terapéutico comprometido y sus implicaciones para el terapeuta}

Consecuentemente, los profesionales optaron por el reconocimiento de la dimensión social y política del individuo como un primer aspecto crucial para el abordaje de la experiencia traumática de la tortura. Planteando su problemática desde una perspectiva psicosocial, se propuso mantener una visión totalizadora, en la que - en primer lugar- era necesario comprender las relaciones entre la represión política y el daño. Esta mirada instaló una relación terapéutica construida sobre el escenario de un compromiso con la realidad sociopolítica, que en sí mismo tenía el fin de recuperar el presente del individuo, es decir, reinsertarlo socialmente y reparar los efectos traumáticos de la violencia.

Basados en esta opción, los profesionales de ILAS acuñaron el concepto de vínculo comprometido (Lira et al. 1991) para aludir a una manera de enfrentar la tarea terapéutica en medio de la represión política. El concepto se refiere a una alianza entre el paciente y el terapeuta a la vez psicológica, política y social, reveladora de una posición ética no neutral frente al padecimiento del sujeto, entendido siempre como resultado de un 
trauma inflingido deliberadamente por razones políticas. El abordaje terapéutico desde esta opción tenía por objetivo recuperar la experiencia como parte de un contexto sociohistórico, recuperando su existencia y realidad, lo que permitiría el resurgimiento de la experiencia subjetiva, en la cual el sufrimiento deja de ser exclusivamente privado, en la medida en que el sujeto puede integrar la dimensión social de este.

La neutralidad, en ese contexto, no era posible, ya que la suspensión de las posturas ideológicas y políticas de los terapeutas podría contribuir a un desconocimiento de la influencia del contexto social en lo psíquico, convirtiendo al terapeuta en reproductor del silencio. En este sentido, los profesionales de EATIP propusieron como alternativa la abstinencia (Kordon 1993), concepto aportado desde el psicoanálisis, en el que se proponía evitar manipular al paciente o satisfacer sus demandas, pero sin apartarse de la actitud interpretativa y la contención, cuidando de no dejar fuera de la relación y de la comprensión del fenómeno, la posición ética, ideológica y política del terapeuta.

La realidad sociopolítica que desde el inicio movilizó la respuesta de los profesionales ante el sufrimiento y la desprotección, se entrecruzaba a cada momento con el quehacer terapéutico. Dicha situación atravesaba a los terapeutas, quienes se veían invadidos por una sobreestimulación de experiencias traumáticas, con una fuerte carga de dolor psíquico, que los afectaba como integrantes de la comunidad y que a la vez les significaba trabajar en condiciones no habituales de amenaza y angustia (Lira et al. 1991). Esta exposición al sufrimiento ponía a terapeutas y equipos, una y otra vez, frente a las limitaciones técnicas y a la propia capacidad de afrontar el sufrimiento. Tal posición obligaba a la puesta en marcha de mecanismos de defensa que permitieran el trabajo con los afectados directos de la tortura. Entre los mecanismos descritos de los terapeutas aparece la disociación como un proceso que tiene a la vez una función instrumental y defensiva. Por otra parte, se describe una actitud frecuente de reparación omnipotente (Bozzolo, en Kordon, Edelman 2005a [1986]), la identificación con las víctimas en su condición de aislamiento social, la idealización de las víctimas y otros mecanismos relacionados con el compromiso político, y la relación entre lo psicológico y lo ideológico.

Durante el período de la dictadura, la realidad contextual se introducía en la relación terapéutica tanto como en otros espacios de la vida cotidiana, afectando tanto a terapeutas como a pacientes, pero sobre todo impactando el modo en que se establecía el vínculo terapéutico. En este sentido, Lira (1996) ha definido el encuentro terapéutico como un encuentro histórico, en el que se entrecruzaban las experiencias del paciente con las de un terapeuta que participaba del mismo momento histórico en que estas se producían y en el que se hacía necesario desentrañar las dimensiones subjetivas del contexto sociopolítico y el rol que tenía la salud mental en el mismo. 
Vol. XXI / № 1 / 2007 / 59-81

\section{Límites de la intervención terapéutica: reparación y reparación social}

A partir de las experiencias de trabajo psicoterapéutico con víctimas PPT, los especialistas acuñaron el concepto de reparación social, tomando el concepto de reparación vinculado al trauma psíquico individual y situándolo desde un contexto psicosocial. Esta trasposición del concepto amplió el espectro de las acciones reparatorias, sacándolas fuera del espacio íntimo de la psicoterapia (Lira, Piper 1997). Desde ahí se hacía posible comprender que era necesario modificar las condiciones políticas que permitieron la ocurrencia de los hechos traumáticos y proponer una política de reparación que abordara las consecuencias de las violaciones a los derechos humanos en los individuos y en la sociedad.

La posición asumida frente a las características particulares del trauma abordado implicó establecer la frontera entre la factibilidad de reparación en el interior del espacio psicoterapéutico y la que quedaba fuera de él. Desde ahí, los terapeutas identificaron un límite a sus posibilidades de acción, pero además adjudicaron una función clara al estado en el restablecimiento de las condiciones que podrían favorecer un avance en la reparación del daño infringido, tanto a los individuos como a la sociedad en general. En primer lugar, demandaban del estado el reconocimiento social de las víctimas como tales y de los acontecimientos como hechos realmente ocurridos, con el fin de desprivatizar el daño, restituir la confianza entre las personas y el estado, y brindar continuidad a la experiencia subjetiva, condición indispensable para el desarrollo de una identidad y de relaciones sanas.

El reconocimiento oficial de la tortura como una práctica sistemática del estado tenía una función irreemplazable en la elaboración individual de la experiencia (Neumann, Erazo 1992; Lira, Piper 1997) y, en lo social, constituía el contexto inicial para enjuiciar lo ocurrido y asegurar que no vuelva a ocurrir. En este sentido, los profesionales advierten que la posibilidad de elaboración del trauma individual y familiar requiere del reconocimiento de los hechos como una verdad oficial, ya que su negación desde el estado formaría parte de la instalación misma del trauma.

\section{La CNPPT: impacto en las víctimas y en la sociedad}

En la transición democrática posterior a la dictadura se aprecian tres instancias promovidas desde el estado para el logro de una reconciliación nacional. El objetivo mayor que sustenta estas iniciativas es el de establecer una verdad histórica compartida, que reconozca los atropellos a los derechos humanos y defina lineamientos para una política de reparación para las víctimas.

La primera instancia corresponde a la Comisión Nacional de Verdad y Reconciliación, constituida por el primer gobierno democrático en 1990 y hecha pública en marzo 
de 1991. Su misión fue la de determinar oficialmente la identidad de los detenidos desaparecidos y de las personas ejecutadas, consignando las circunstancias de sus muertes. Fue creada sobre la base de dos premisas: "Es sólo sobre en base a la verdad que será posible satisfacer a las exigencias fundamentales de la justicia y crear las condiciones indispensables para lograr una reconciliación nacional efectiva" y "sólo la verdad podrá rehabilitar públicamente las víctimas" (Comisión Chilena de Derechos Humanos, Informe Rettig 1991).

El trabajo de esta comisión finalizó con un informe exhaustivo que retoma toda la información relativa a las víctimas de la represión de militares y particulares: desaparición de personas, detenciones, ejecuciones, torturas con resultado de muerte, en los que el estado chileno, por las acciones de sus agentes, es el responsable; y atentados cometidos por particulares bajo pretextos políticos. Este trabajo permitió identificar a más de 3.200 personas que fueron objeto de represión política con causa de muerte.

Posteriormente, el año 2001 se convocó a diferentes representantes de la sociedad civil, política, de las Fuerzas Armadas y del ámbito de los derechos humanos para establecer una instancia de reencuentro basada en la tolerancia y la transparencia. La iniciativa dio forma a la Mesa de Diálogo, cuya intención fue lograr ciertos acuerdos básicos respecto de los acontecimientos de nuestro pasado reciente y esclarecer algunos casos de detenidos desaparecidos y ejecutados políticos. Lamentablemente, hoy sabemos que muchas de las informaciones entregadas resultaron ser falsas, lo que implicó ampliar la brecha entre distintos sectores de la sociedad y una traba al objetivo de reconciliación nacional.

Finalmente, en el período del Presidente Lagos, este dio a conocer en agosto de 2003 su propuesta en materia de derechos humanos - No hay mañana sin ayer-, a partir de la cual se formó la CNPPT. El objetivo de esta Comisión fue "determinar, de acuerdo a los antecedentes que se presenten, quiénes son las personas que sufrieron privación de libertad y torturas por razones políticas, por actos de agentes del Estado o de personas a su servicio, en el período comprendido entre el 11 de septiembre de 1973 y el 10 de marzo de 1990" (DS 1.040). Se trató entonces de que los propios sobrevivientes declararan, reconociendo y abordando las prácticas de PPT ocurridas.

El trabajo realizado por todas estas comisiones ha sido analizado bajo diversas perspectivas. Desde un punto de vista histórico, Pérotin-Dumon (2005) señala que los informes emanados de las comisiones otorgaron un carácter público a una verdad conocida por muchos, pero sólo afirmada por las víctimas, sus familiares y organismos de defensa de los derechos humanos; estos documentos habrían entonces determinado un proceso de reconocimiento social de lo que pasó.

Otro análisis, realizado a partir de un pormenorizado estudio de archivos históricos, indica que todas estas iniciativas se enmarcarían en la llamada "vía chilena de reconciliación”, descrita por Loveman y Lira (1999, 2000). Estos autores sostienen que el ciclo de ruptura y de intentos de restauración de la paz se ha repetido muchas veces en Chile, 
Vol. XXI / № 1 / 2007 / 59-81

dando lugar a una vía de reconciliación política en donde los políticos se han transformado en expertos de correr el velo del olvido, erigiendo el perdón jurídico a base de amnistías e indultos, "la sociedad parecía haber aprendido a olvidar las heridas y el dolor de las rupturas, sin olvidar, olvidando que fue necesario olvidar y sin saber que no se ha olvidado definitivamente" (Loveman, Lira 1999:9).

\section{El funcionamiento de la CNPPT}

La CNPPT surge de la necesidad de reconocer, ya no a los desaparecidos o a los muertos, sino a los sobrevivientes de las violaciones llevadas a cabo en nuestro país, específicamente de la PPT (CNPPT 2005). Es importante recalcar que el papel de esta Comisión nunca fue el de encontrar o sancionar a culpables de los abusos cometidos; el mandato en este sentido era claro: registrar a las víctimas, no a los victimarios.

La Comisión se dividió en dos estructuras fundamentales, con funciones definidas y complementarias: la Comisión, estructura de carácter resolutivo, integrada por los comisionados, y la Vicepresidencia Ejecutiva, estructura operativa, de carácter propositivo, integrada por equipos profesionales, técnicos y administrativos (CNPPT 2005). Las funciones fueron, principalmente, acordar criterios de calificación y métodos de validación de los antecedentes, solicitar información a otras entidades estatales, formular los comunicados públicos y elaborar el Informe.

La Vicepresidencia Ejecutiva estuvo conformada por cuatro áreas: atención de público, información e investigación documental, calificación y administración y finanzas; y dos unidades de apoyo: procesamiento y archivo, y apoyo informático. El área de atención de público fue la encargada de coordinar la recepción de testimonios y antecedentes de las víctimas (o de sus familiares en caso de que hubieran muerto) a lo largo de todo el país. Para ello se formaron dos equipos, uno a cargo de la Región Metropolitana y otro de la atención en regiones, en 42 gobernaciones. Ambos equipos estaban principalmente formados por abogados, psicólogos y asistentes sociales. Si bien las gobernaciones se organizaron de modo local (designando a personal para las tareas), las 13 más pobladas recibieron apoyo de profesionales especialmente contratados para ello y supervisión por parte del equipo de la zona central, con el fin de colaborar en la recolección de antecedentes en las zonas más aisladas del país (CNPPT 2005).

El primer paso del proceso de recolección de antecedentes consistía en que las víctimas que quisieran declarar en la Comisión debían retirar su Ficha de Antecedentes, ${ }^{6}$ disponible en distintos lugares designados para ello. Luego de tener esta ficha en su poder y de haberla completado hasta donde les fuera posible, debían solicitar una entrevista, la

6 Disponible en http://www.comisiontortura.cl/index.html 
cual duraba aproximadamente una hora. Anticipando esto, los profesionales "recibieron orientaciones y recomendaciones destinadas a facilitar la creación de una atmósfera de respeto y confianza, para generar de ese modo un ambiente adecuado para la entrega de la información o antecedentes y garantizar su reserva y confidencialidad" (CNPPT 2005:40).

Muchos testimonios significaron para las víctimas su primer relato acerca de lo que les había ocurrido, un proceso de recuerdo inevitablemente doloroso que el profesional debía acoger con cuidado y sin generar expectativas que no estuvieran dentro de los límites del mandato de la Comisión. Aclarar estos límites y reservarse de tomar una posición política al momento de entrevistar eran disposiciones que el profesional debía tener en cuenta con el fin de mantener el sentido de neutralidad e imparcialidad de la Comisión.

El análisis de casos fue encargado al área de calificación, cuyo objetivo fue "evaluar, caso por caso, los antecedentes de detención o tortura presentados, identificando los elementos de juicio que permitieran formar convicción y proponer una precalificación para ellos" (CNPPT 2005:35), precalificación que luego sería discutida y analizada más a fondo por los comisionados. Para tomar la decisión respecto de la precalificación, los profesionales de esta área podían recurrir a distintos procedimientos, entre los cuales estaba incluso la posibilidad de efectuar una segunda entrevista a la víctima en cuestión.

\section{El Informe de la CNPPT}

El Informe de la CNPPT (también conocido como Informe Valech) se hizo público el 28 de noviembre de 2004. Contiene una descripción de lo que fue el contexto político y social en que PPT se instalaron como recursos masivos y sistemáticos de control y represión, provenientes de una política de estado.

La Comisión reunió los antecedentes de 35.868 personas. Un 37\% de los testimonios se recibió en la Región Metropolitana, un 54\% en regiones y un 9\% en el extranjero. Las regiones donde más se atendió fueron la VII, la V, la IX y la X, mientras que los países del extranjero donde se reportaron más casos fueron Canadá y Argentina, seguidos por Suecia y Francia (CNPPT 2005).

Se calcula, sin embargo, que un número importante de personas decidió no declarar en la Comisión, ya sea por desesperanza, temor, falta de fuerza para hacerlo, diferencias políticas con el gobierno, desinformación, entre otros motivos (Riquelme, Cruz 2005).

De todos los antecedentes recibidos, la Comisión calificó 27.255 casos, cifra correspondiente a un $76 \%$ del total de testimonios recibidos. ${ }^{7}$ De ellos, un $87,5 \%$ fueron

Es importante considerar que el 90\% de los declarantes señaló haber sufrido tortura mientras estuvo en prisión, cifra que dificultó la separación o delimitación de ambas situaciones. 
Vol. XXI / № 1 / 2007 / 59-81

hombres y un 12,5\% mujeres. Cabe señalar que casi todas las mujeres afirmaron haber sido violentadas sexualmente, situación que por su brutalidad fue considerada especialmente en el Informe. Con respecto a la edad al momento de la detención, un 44,2\% de los calificados tenía entre 21 y 30 años, $25,4 \%$ entre 31 y 40 años, $12,5 \%$ entre 41 y 50 años y $9,7 \%$ entre 18 y 20 años. Los menores de 18 años conformaron un 4\%, 88 de los cuales eran menores de 12 años (CNPPT 2005).

En su tarea, la Comisión se encontró con situaciones especiales que fueron posteriormente integradas a su mandato. Fue el caso de los menores de edad (algunos detenidos en forma individualizada y otros junto a sus padres, en razón de la detención de estos), así como el de niños que nacieron en cautiverio. Quizá los casos más difíciles de considerar fueron los de quienes estaban en gestación cuando sus madres fueron detenidas y de quienes fueron engendrados como producto de violaciones sexuales cometidas durante la detención de sus madres. En ambos casos, las madres dieron a luz ya en libertad; los primeros fueron considerados como parte de la categoría de menores detenidos junto a sus padres y los segundos como víctimas directas (CNPPT 2005). En total, los casos de menores de 18 años que calificaron alcanzaron a 105 casos.

La Comisión no sólo tenía por objeto calificar a las víctimas de PPT durante el régimen militar, sino que además debía proponer medidas de reparación. Estas medidas abarcaron los ámbitos jurídico, económico, moral, de salud y social; y mientras las medidas individuales estaban dirigidas a las víctimas mismas, las colectivas tuvieron un carácter simbólico y moral, en busca de ejercer un efecto a nivel social, crear una conciencia con respecto a lo acontecido en nuestro país y promover su no repetición en el futuro.

Los objetivos generales de las medidas de reparación propuestas fueron dos. Por un lado, la idea de hacer justicia a través de medidas integrales, es decir, debían responder a las distintas necesidades de las víctimas, individuales como colectivas, materiales como simbólicas, referidas estas últimas al restablecimiento de su honor y dignidad, al reconocimiento social de lo ocurrido y a la garantía de que nunca más ocurrirá. Además, las medidas reparatorias tenían fines más específicos, como el reconocimiento de las víctimas como individuos y como ciudadanos, es decir, un cambio en su situación subjetiva; se buscaba reintegrarlas a la sociedad y sacarlas de la marginalidad en la que vivieran las consecuencias de la PPT. Por otro lado, se intentó reestablecer la confianza cívica entre los ciudadanos, reconstituir los lazos rotos y reconciliar a las distintas partes de la sociedad chilena. Finalmente, las medidas se instalaron como una muestra de solidaridad, tanto a nivel social como individual, en el sentido de integrar a las víctimas al tejido social, sobre la base de que las otras partes de la sociedad han podido ponerse en su lugar y reconocer su injusticia (CNPPT 2005). 


\section{El impacto de la CNPPT}

Analizar cuál ha sido el impacto que tuvo la creación de la CNPPT y la publicación oficial del Informe, debe ser hecho considerando a diferentes actores. Están las propias víctimas que decidieron acudir a declarar a la Comisión. Está también la sociedad chilena que recibe la información contenida en el Informe. Están asimismo los profesionales encargados de recoger estos testimonios, para muchos de los cuales esto resultó una experiencia de gran impacto que los ha conmovido y en múltiples casos angustiado (Lira 2004).

Respecto al impacto en las víctimas, siguiendo las reflexiones de los profesionales que trabajan con ellas (Aguilar, Díaz, Gómez 2005), es posible distinguir al menos tres situaciones. La de personas que, estando en procesos terapéuticos, se ven enfrentadas a partir de la Comisión a ciertos procesos caracterizados por reacciones emocionales intensas, ambivalentes y contradictorios, y en donde en algunos casos se utiliza el espacio terapéutico para deliberar acerca de la posibilidad de entregar el testimonio. Está también la situación de personas que luego de más de 30 años deciden contar por primera vez su experiencia de prisión y tortura ${ }^{8}$ y que luego de entregar su testimonio son derivadas por la Comisión a instancias especializadas. En ambos casos, el declarar ante la Comisión ha significado "un intento de recuperar y cerrar significados, de completar el sentido de las propias opciones en sus vidas, en las que han debido batallar contra la reinterpretación ideológica y cultural de su propio pasado, de sus proyectos y de su pertenencia a esta sociedad" (Lira 2004:5).

Finalmente, está el caso de familiares directos de personas que fueron torturadas y en donde el testimonio de su familiar ha afectado su propio proceso terapéutico y ciertamente su vida.

Los profesionales especializados en estas temáticas coinciden en señalar que la creación de la CNPPT y la publicación del Informe permiten que el trauma de origen social fuera reconocido al nivel que se había producido, es decir, a nivel social (Barría, Gómez, Piper 2005), siendo el estado — causante de estos maltratos— el que reconocía su responsabilidad y se disponía a escuchar el testimonio de las víctimas, reconociéndolas como tales e intentando de alguna manera reparar.

Respecto del impacto a nivel social de la CNPPT y del Informe, este puede ser analizado desde varios ángulos, como el que reflejan las encuestas de opinión pública, lo que la prensa nacional e internacional informaron al respecto y también retomando lo que los mismos profesionales que trabajan en derechos humanos han señalado.

En las encuestas de opinión pública se aprecia que el tema de los derechos humanos ha estado presente transversalmente, como un asunto pendiente que debe ser resuelto,

8 De acuerdo al Informe, se estima en un $80 \%$ de los declarantes a la Comisión, las personas que no habían contado nunca antes su experiencia. 
Vol. XXI / № 1 / 2007 / 59-81

siendo el gobierno el organismo llamado a abordarlo (CEP 2005, 2004, 2003, 2001, 1991). ${ }^{?}$

En el año 2004, al momento de la publicación del informe de la CNPPT, se realizaron varias encuestas que versaban sobre la atingencia y relevancia de este trabajo. Uno de los estudios realizados fue llevado a cabo por la Fundación Futuro, en diciembre de 2004. ${ }^{10}$ Por su parte, el Centro de Estudios Públicos (CEP), dentro del estudio nacional de opinión pública llevado a cabo en diciembre de $2004,{ }^{11}$ también aborda la publicación del Informe de la CNPPT.

La mayoría de las personas encuestadas (74\%) aprueba el Informe realizado por la Comisión Valech (Fundación Futuro 2004), el que goza de una alta credibilidad respecto de su contenido; esta cifra decae, de acuerdo al CEP, a un $48,8 \%$, y el $28,4 \%$ cree que el Informe tiene algo de verdad pero también mucha exageración y mentira (CEP 2004).

El Informe de la CNPPT es considerado como un aporte a la búsqueda de verdad, justicia y reconciliación por un $71 \%$ de las personas (Fundación Futuro 2004). Sin embargo, existe la creencia en el 50,9\% de los consultados de que el Informe ayudará a reabrir las heridas del pasado, más que a cerrarlas (CEP 2004), pero que en el futuro este ayudará a generar confianza y paz social entre los chilenos (53\%).

La mayoría cree que el Informe debiera difundirse, analizarse y debatirse en los colegios y/o universidades (74\%), mientras que el $22 \%$ piensa lo contrario. Es importante destacar el hecho de que quienes aprueban, validan y quieren la difusión del Informe, son en gran porcentaje personas que pertenecen a los estratos socioeconómicos medio y bajo, y que además son simpatizantes del gobierno (Fundación Futuro 2004), lo que concuerda con la percepción de 'unilateralidad partidista' abocada al tema.

La publicación del Informe fue propicia para que la población estuviera en conocimiento de una parte de la historia del país, ya que si bien un $62 \%$ de las personas declaró haber sabido de los hechos que ocurrían durante la dictadura militar, un 34\% de la población no lo sabía ni intuía (Fundación Futuro 2004, CEP 2004). El tema de los atropellos a los derechos humanos ocurridos en Chile pasó a ocupar un lugar privilegiado al momento de la publicación del Informe, lo que se vio reflejado en que la mayoría de las personas conversaron con sus familias sobre el Informe (59\%), mientras que un $53 \%$ lo abordó como tema de conversación entre amigos y un 42\%, entre compañeros de trabajo (Fundación Futuro 2004).

9 Los estudios citados se encuentran disponibles en http://www.cepchile.cl

10 Encuesta realizada con una muestra de 400 personas, por medio de una encuesta telefónica, representando el $76 \%$ de la población total del país. Para mayor información, dirigirse a: http://www.fundacionfuturo.cl/ad$\mathrm{min} /$ publicos/InformeValech.PDF

11 Encuesta realizada a 1.505 personas. 
Así, también, se observa que la gente considera necesario que personas e instituciones con alguna responsabilidad en los atropellos denunciados debieran pedir perdón (84\%), pero, por sobre todo, el Informe se considera como una ayuda para que no se repitan en Chile casos de atropello a los derechos humanos (84\%) (Fundación Futuro 2004).

Respecto de lo que apareció en la prensa, los titulares del 29 de noviembre de 2004 amanecieron impregnados con la noticia que el Presidente había dado a conocer por cadena nacional la noche anterior: "Gobierno reconoce torturas como práctica institucional de Estado" (La Nación, "País", 29/11/04). La lucha por las responsabilidades con respecto a las violaciones reconocidas en el Informe no tardó en instalarse en los medios: "La Concertación pide que la derecha asuma culpas" (La Nación, "País", 30/11/04); "Torturas: comisión política de RN descartó asumir responsabilidad como partido" (Radio Cooperativa, "Nacional", 29/11/2004). Las reacciones de las principales instituciones responsables también tuvieron un lugar primordial en los titulares: "Armada 'acoge' Informe Valech y reconoce que sus miembros torturaron" (Radio Cooperativa, "Nacional", 30/11/04); "Torturas: Gendarmería afirmó que 'si tenemos responsabilidad, asumimos plenamente" (Radio Cooperativa, "País", 30/11/04).

La desilusión de quienes trabajan con el tema de derechos humanos fue asimismo ampliamente considerada: "Coordinadora de ex presos políticos consideró 'parcial e insuficiente' al Informe Valech" (Radio Cooperativa, "Nacional", 28/11/04); "Grupo de derechos humanos cree que mayoría de los torturados quedó fuera del Informe Valech" (Radio Cooperativa, "Nacional", 30/11/04). Finalmente, el tema de la reparación también estuvo presente: "Ajuste presupuestario y reservas del Fisco sustentarán reparaciones a torturados" (La Tercera, "Política", 29/11/04). Así, las opiniones de los distintos sectores de la sociedad chilena se fueron dando a conocer por medio de la prensa nacional, generando debates en torno a la publicación del Informe.

Pero el Informe no fue solamente comentado por la prensa nacional sino que también figuró en los titulares de todo el mundo. La compensación económica que recibirán las víctimas y el reconocimiento de que la tortura fue una 'política de estado' es lo más destacado en los despachos de prensa. La palabra 'horror' es el término que más se repite para calificar el contenido del documento (Secretaría de Comunicación y Cultura 2004).

\section{Discusión}

La existencia de PPT en el régimen dictatorial chileno es un conocimiento inscrito en la historia del país, así como las muertes, exilios y desapariciones. Este conocimiento, sin embargo, ha sido negado sistemáticamente a nivel social, significando para las víctimas una condición que mantiene las consecuencias traumáticas de tales experiencias. Fenómenos como la privatización del daño (Kordon, Edelman 2005a [1986]) llevan consigo nuevas consecuencias que se suman a los daños directos de la PPT, a nivel individual y colectivo. 
Vol. XXI / № 1 / 2007 / 59-81

La reparación de las secuelas de la PPT no puede ser reducida a la intervención médica, psicológica y/o social con víctimas, lo cual mantendría la privatización del daño a través de la individualización de la reparación, negando la responsabilidad del estado chileno en la reparación de los daños provocados, lo que podría sugerir procesos de privatización de la reparación.

Es preciso el reconocimiento público de estos hechos para intentar reparar los daños provocados con estas prácticas, restituyendo la condición de sujeto político que ha sido violentada y del cuerpo social en su conjunto, asumiendo que una parte del dolor y del trauma no será posible elaborar ni reparar, ni en las víctimas ni en la sociedad.

La CNPPT, así como comisiones precedentes (Rettig y Mesa de Diálogo) han intentado realizar aquello que las experiencias de intervención psicosocial con víctimas han sostenido necesario para la elaboración del trauma y la reparación de la subjetividad dañada: la validación a nivel social de lo ocurrido, proceso inverso a la privatización del daño. Si bien un objetivo común a estas instancias fue intentar asentar un marco histórico consensuado respecto de lo sucedido, cada una de ellas lo hizo en temáticas diferentes, respectivamente, detención con causa de muerte, destino de los detenidos desaparecidos y PPT, las que por primera vez en treinta años fueron objeto de políticas de reparación a través de una Comisión. El mismo estado que dañó, esta vez escucha e intenta reparar.

Puede decirse que la CNPPT permitió instalar la temática en las conversaciones cotidianas y en la agenda pública del período en el cual operó, especialmente al momento de su creación y la entrega pública del Informe. De esta forma, permitió romper el cerco de sectores políticos, organizaciones de familiares de víctimas e instituciones de salud mental y derechos humanos, en los cuales había quedado circunscrito el tema, a pesar de los esfuerzos por hacerlo público.

El reconocimiento oficial por parte del estado, propuesto como una de las medidas de reparación, no sólo fue un gesto simbólico, sino que afectó y constituyó nuevas prácticas sociales en distintos niveles de la sociedad chilena. En el ámbito sociocultural surgen expresiones artísticas en el cine, teatro, danza y plástica, que dan cuenta de la PPT (Riquelme, Cruz 2005). Surgen también programas de derechos humamos, encuentros de antiguos detenidos y se crean agrupaciones de menores víctimas de tortura.

La tortura llega a ser un tema de conversación social y los hijos de las más diversas familias interrogan a sus padres sobre la historia del país. Los chilenos somos confrontados con nuestras historias personales como partícipes de la sociedad que conformamos. Resulta interesante que una gran cantidad de personas, según lo reportan las encuestas señaladas, habló de este tema con amigos, familiares o compañeros de trabajo, tras la publicación del Informe.

Sin embargo, pese al impacto que esta situación causó en el país y a que un 75\% de la población se inclina porque este tema siga siendo debatido en universidades y colegios, la mitad de los chilenos parece creer aún que hablar de PPT es abrir heridas del pasado, las cuales es mejor dejar cicatrizar en el olvido. 
En este sentido, aproximadamente un tercio de la población declara no saber de la existencia de PPT en el país, cifra que junto al sentimiento que hablar sobre ellas puede reabrir heridas, resulta indicativa de la eficiencia que, aún en la actualidad, poseen las dinámicas producidas por la violencia organizada y la privatización del daño, dinámicas que continúan facilitando el cumplimiento de los objetivos de la PPT: mantener el control social ocultando las estrategias represivas.

Así, también, podría pensarse que si bien un amplio número de chilenos es consciente de la necesidad de que el tema sea público, se prefiere que quede en un espacio cerrado (víctimas, organismos de derechos humamos, academia) sin que involucre a las vidas privadas ni que irrumpa en la cotidianidad, pues es un tema ominoso ${ }^{12}$ (Freud 1919), en tanto víctimas, victimarios y sus descendencias están insertos en nuestra trama social cotidiana.

De esta manera, se despliegan varios temas pendientes a partir del trabajo de la CNPPT. Se considera relevante ahondar en el impacto que la CNPPT tuvo en las víctimas que acudieron a presentar sus testimonios (muchas veces relatados por primera vez en treinta años), en la ciudadanía en su conjunto, que conoció la versión oficial de estos hechos, y también en los profesionales que escucharon directamente estas historias, con los consecuentes desafíos profesionales implicados en este trabajo. ${ }^{13}$

Este impacto resulta particularmente relevante de estudiar, reflexionando en torno a la posibilidad de elaboración de lo traumático desde instancias estatales como la propuesta por la CNPPT. La Comisión instauró un momento histórico, sólo un momento, en el que las víctimas pudieron dar su testimonio. Sólo una vez los profesionales, encomendados por el estado, accedieron a la escucha de estos testimonios. El Informe se hizo público sólo una vez. ¿¿Sólo una vez este tema será abierto públicamente en la sociedad chilena? ¿Es posible la elaboración individual y social de lo traumático bajo estas circunstancias?

Desde estas interrogantes emerge otra línea de investigación respecto del impacto que tendrá el reconocimiento de hechos de una historia social traumática en las generaciones posteriores y en la memoria histórica colectiva que se construye de los acontecimientos de nuestro pasado como país. Queda planteada la cuestión de la divulgación y del traspaso generacional, evitando así que el espacio social que abrió la CNPPT se cierre junto con la última página de su Informe, como ha sucedido históricamente con estas instancias en el país, tal como sugieren Loveman y Lira (1999).

\footnotetext{
Algo familiar, a la vez desconocido. Algo terrorífico, que muestra la desarticulación de lo humano.

13 Actualmente está en curso una investigación a cargo de los autores de este trabajo, la que intenta conocer y comprender el impacto que la experiencia de recepción de los testimonios de PPT tuvo en los profesionales de la CNPPT.
} 
Finalmente, al quedar excluido del mandato de la Comisión, conocer la identidad de los victimarios es una cuestión aún no resuelta, asunto que deviene necesario por motivos judiciales y políticos, pero también respecto del propósito de conocer el impacto que esta experiencia tuvo, sin duda, en sus vidas.

Sólo se abre la posibilidad de comenzar a superar la orfandad de memoria recuperando esta parte de nuestra historia. En este sentido, la imagen de un ciudadano festejando en las calles de Santiago la muerte de Pinochet, ${ }^{14}$ llevando en alto el Informe de la CNPPT, así como otros familiares llevaban las fotos de sus muertos y desaparecidos, puede resultar ilustrativa de estas ideas. No negar, sino que aceptar y asumir nuestra historia, parece ser relevante no sólo por la construcción de una memoria colectiva, sino porque esta historia está entramada con la subjetividad de cada uno de los sujetos sociales que la conformamos.

\section{Referencias bibliográficas}

Agger, Inger, Soren Buus Jensen, 1996. Trauma y cura en situaciones de terrorismo de estado. Santiago: Ediciones Chile-América CESOC.

Aguilar, María Inés, Margarita Díaz, Elena Gómez, 2005. "Análisis de los efectos psíquicos asociados al impacto del Informe en la elaboración de lo traumático en procesos terapéuticos individuales". RevistaVirtu@l Ilas, 4. Disponible en: http://www.ilas.cl/revi_4.html [octubre 2006].

Azócar, María Luisa, María Teresa Casté, Pilar Soza, 2003. "El conflicto político: lo innombrable del conflicto psíquico". Gradiva, 4, № 2, 142-150.

Barría, Cristián, Elena Gómez, Isabel Piper, 2005. "La construcción de la memoria del trauma sociopolítico en el espacio intersubjetivo”. Revista Virtu@l Ilas, 4. Disponible en: http://www. ilas.cl/revi_4.html [octubre 2006].

Castillo, María Inés, Elena Gómez, 2005. "Construyendo colectivamente la memoria omitida. El contexto del Informe de la CNPPT”. RevistaVirtu@l Ilas, 4. Disponible en: http://www. ilas.cl/revi_4.html [octubre 2006].

CEP (Centro de Estudios Públicos), 1991, 2001, 2003, 2004, 2005. Disponibles en: http:// www.cepchile.cl [junio, octubre 2006].

Chasseguet-Smirgel, Janine, 1986. Ética y estética de la perversión. Barcelona: Laia.

Collarte, Paula, María Inés Villanueva, 1992. La tortura desde una perspectiva psicológica. Características, efectos y terapia. Revisión bibliográfica. Memoria (Lic.), Escuela de Psicología, Universidad Católica de Chile.

14 Pinochet murió el día del aniversario de la proclamación de la Declaración Universal de los Derechos Humanos, el 10 de diciembre de 2006, mientras este artículo estaba en redacción. 
Comisión Chilena de Derechos Humanos, 1991. Nunca más en Chile. Sintesis corregida y actualizada del Informe Rettig. Santiago: Lom.

Comisión Nacional sobre Prisión Política y Tortura, 2004. Informe. Disponible en: http://www. gobiernodechile.cl/comision_valech/index.asp [mayo 2005].

Cornejo, Marcela, Germán Morales, Dariela Sharim, Juana Kovalskys, 2006. Del testimonio al relato de vida: procesos elaborativos en profesionales de la Comisión Nacional sobre Prisión Política y Tortura. Proyecto Fondecyt No 1070855.

Díaz, Margarita, 2005. "Aspectos clínicos del reconocimiento y reconstrucción e la subjetividad en pacientes severamente traumatizados”. RevistaVirtu@l Ilas, 4. Disponible en: http://www. ilas.cl/revi_4.html [octubre 2006].

Espínola, Mercedes, Daniel Gil, Marta Klingier, Elsa Leone, 1985. "Consecuencias de la tortura para el individuo, la familia y la sociedad”. Ponencia presentada en el Seminario Internacional La Tortura en América Latina. Montevideo, 1985. Disponible en: www.smu.org.uy/emc/novedades/ddhh/tortura/a55-58.pdf [octubre 2006].

Freud, Sigmund, 1919. "Lo ominoso”. Obras completas. Vol. 17. Buenos Aires: Amorrortu. 1927. "El fetichismo". Obras completas. Vol. 21. Buenos Aires: Amorrortu.

Fundación Futuro, 2004. "Estudio de opinión pública: Informe de la Comisión sobre Prisión Política y Tortura”. Disponible en: http://www.fundacionfuturo.cl/admin/publicos/InformeValech.PDF [octubre 2006].

Garcés, Mario, Nancy Nicholls, 2005. Para una historia de los derechos humanos en Chile. Santiago: Lom-FASIC.

Gómez, Elena, 1985. “La tortura como experiencia traumática. Perspectivas del Daño”. Ponencia presentada en el Seminario Internacional La Tortura en América Latina. Montevideo, 1985. Disponible en: www.smu.org.uy/emc/novedades/ddhh/tortura/a59-63.pdf [octubre 2006].

Ibacache, Luis, Jaime Meléndez, Luisa Castaldi, Margarita Cabrera, Héctor Vega, 1991. "Las huellas del miedo. La represión política: daño y reparación”. En Codepu, ed. Persona, estado, poder. Estudios sobre salud mental. Santiago: Codepu, 29-39.

Kordon, Diana, 1993. "La tortura en Latinoamérica: sus efectos inmediatos y mediatos en el individuo y en la sociedad". Disponible en: http://www.eatip.org.ar/textos/latorturaenlatinoamericasusefectos.pdf [agosto 2006].

Kordon, Diana, Lucila Edelman, 2005a [1986]. "Efectos psicológicos de la represión política". En Diana Kordon, Lucila Edelman, Darío Lagos y Daniel Kersner, eds. Efectos psicológicos y psicosociales de la represión política y la impunidad. Buenos Aires: Ediciones Madres Plaza de Mayo, 37-44.

2005b [1995]. "Efectos psicosociales de la impunidad”. En Diana Kordon, Lucila Edelman, Darío Lagos y Daniel Kersner, eds. Efectos psicológicos y psicosociales de la represión política y la impunidad. Buenos Aires: Ediciones Madres Plaza de Mayo, 125-140.

, 2005c [1995]. “Trauma y duelo. Conflicto y elaboración”. En Diana Kordon, Lucila Edelman, Darío Lagos y Daniel Kersner, eds. Efectos psicológicos y psicosociales de la represión politica y la impunidad. Buenos Aires: Ediciones Madres Plaza de Mayo, 201-210. 
Vol. XXI / № 1 / 2007 / 59-81

Lira, Elizabeth, 1992a. El impacto del sufrimiento en el terapeuta. Santiago: ILAS. , 1992b. Violaciones de los derechos humanos en Chile: discernimientos acerca de las consecuencias en los terapeutas. Santiago: ILAS.

2004. "Del reconocimiento a la reparación". Mensaje, mayo, 2004. Disponible en: http://www.dawson2000.com/comisionprision1.htm [mayo 2005].

Lira, Elizabeth, David Becker, María Isabel Castillo, 1991. Derechos humanos: todo es según el dolor con que se mira. Santiago: ILAS.

Lira, Elizabeth, Isabel Piper, 1997. Subjetividad y politica. Diálogos en América Latina. Santiago: Ediciones Chile-América, CESOC.

Lira, Elizabeth, Eugenia Weinstein, Sofía Salamovich, 1986. "El miedo: un enfoque psicosocial”. Revista Chilena de Psicología, 8, 51-56.

Loveman, Brian, Elizabeth Lira, 1999. Las suaves cenizas del olvido. Via chilena de reconciliación politica 1814-1932. Santiago: Lom.

Madariaga, Carlos, 2002. "Trauma psicosocial, trastorno de estrés postraumático y tortura". Disponible en: www.cintras.tie.cl/textos/monog_trauma_psicosocial_espanol.pdf [octubre 2006].

Milos, Pedro, 2003. “¿Huérfanos de memoria?” Mensaje, Edición Especial: Chile, 30 años después, $\mathrm{N}^{\circ}$ 522, 330-34.

Neumann, Elisa, Rodrigo Erazo, 1991. "Significado psicosocial de la tortura”. En II Seminario de la Región del Maule. Derechos Humanos, Salud Mental, Atención Primaria: Desafío Regional. CINTRAS, Chile.

Pérotin-Dumon, Anne, 2005. "El pasado vivo de Chile en el año del Informe sobre la Tortura”. Nuevo Mundo Nuevos Mundos, 5. Disponible en: http://nuevomundo.revues.org/docment954.html [septiembre 2005].

Puget, Janine, 2006. "Violencia social y psicoanálisis. De lo ajeno estructurante a lo ajeno-ajenizante”. En Janine Puget y René Kaës, comps. Violencia de estado y psicoanálisis. Buenos Aires: Lumen, 25-56.

Rey, Norberto 1985. “Tortura institucionalizada: régimen carcelario”. Ponencia presentada en el Seminario Internacional La Tortura en América Latina. Montevideo, 1985. Disponible en: www.smu.org.uy/emc/novedades/ddhh/tortura/a73-82.pdf [octubre 2006].

Riquelme, Jacqueline, Gloria Cruz, 2005. "Impacto de la Comisión Nacional sobre Prisión Política y Tortura en Chile”. RevistaVirtu@l Ilas, 4. Disponible en: http://www.ilas.cl/revi_4.html [octubre 2006].

Rojas, Paz, 1994. "Algunas reflexiones sobre rehabilitación de personas torturadas". En Codepu, ed. Persona, estado, poder. Estudios sobre salud mental. Santiago: Codepu, 129-138.

Rojas, Rodrigo, 2000. "Trauma, escisión y adaptación: Ferenczi, antecedentes de Winnicott”. Gradiva, 1, № 2, 179-190.

Secretaría de Comunicación y Cultura. Departamento de Prensa Internacional. "Chile en la Prensa Internacional". 2 de diciembre de 2004. 